\title{
A Framework for Supporting Rainwater Harvesting in the UK
}

\author{
S. Ward*, D. Butler* S. Barr** and F. A. Memon* \\ * Centre for Water Systems, University of Exeter, North Park Road, Exeter, EX4 4QF, UK \\ (E-mail: sw278@exeter.ac.uk; d.butler@exeter.ac.uk; f.a.memon@exeter.ac.uk) \\ ** Department of Geography, University of Exeter, Rennes Drive, Exeter, EX4 4RJ, UK \\ (E-mail: s.barr@exeter.ac.uk)
}

\begin{abstract}
Numerous policy vehicles have been introduced in the UK, which promote the use of rainwater harvesting (RWH). However, an 'implementation deficit' exists where legislation limits action by failing to provide adequate support mechanisms. This study uses an interdisciplinary approach to construct a framework to address the issue of overcoming this deficit. Evidence bases have identified six deficit categories, which confirm a lack of enabling of stakeholders. Outline recommendations, such as coordinated information provision and reconsideration of incentive schemes are made in relation to these categories to complete the framework for supporting RWH in the UK.
\end{abstract}

Keywords

Evidence; framework; grounded theory; rainwater harvesting; stakeholder

\section{INTRODUCTION}

Within the UK, demand management measures are increasingly being implemented to achieve water efficiency programme goals. When the demand reduction limits of such programmes are reached Hassell (2005) argues, the next step will be to incorporate supplementary resources, such as rainwater harvesting (RWH). Although RWH is currently experiencing increased interest, a number of barriers exist in supporting its implementation for a range of stakeholders. For example, unlike other water efficiency measures (such as low flush toilets), RWH has significant cost implications (installation and maintenance), external constraints (supply/demand balance) and inclusion issues (eligibility for financial assistance). Effectively this results in what Robinson (2006) terms (in the context of GHG emissions) as an 'implementation deficit' resulting from a gap between planning goals and actions. The first question is why does this implementation deficit exist for RWH? Are expectations/ambitions set too high or are policies, incentives and support mechanisms not fit for purpose?

In the UK there has been a period where broad policy statements were low on detailed recommendations (the various Planning Policy Statements). Bulkeley (2006) highlights that in a spatial planning context national policy guidance in relation to water supply is fragmented. She asserts that "while issues of energy supply and conservation have to date been weakly developed within planning policy, those surrounding water are notable by their absence in most cases". Although this is beginning to change there is still the issue of making any recommendations obligatory. In the context of sustainable development, the Sustainable Buildings Task Group (2004) reinforce this stating: "[PPS1] needs to be much clearer about the extent to which the planning system can require more sustainable building practices in support of the new sustainable development duty, as opposed to merely encouraging or promoting them." 
A prime example of this is the Code for Sustainable Homes (CSH), first introduced in 2006, which promotes the use of RWH. The CSH is a voluntary code rather than a mandatory standard - in practice it is merely a series of recommendations which developers can chose to adhere to or not. Even social housing funded through the Housing Corporation only has to be built to Code level 3, which (for water) has a performance standard of $105 \mathrm{l} / \mathrm{p} / \mathrm{d}$, representing current best practice in water efficiency without requiring water reuse or rainwater harvesting (DEFRA, 2008a). Although this is a positive step, it falls somewhat short of the ambition of the Progress Report on Sustainable Products and Materials' vision for building and construction that: "Water re-use systems such as rainwater-harvesting and grey water systems - to provide water for toilet flushing and outside use - are standard" (DEFRA, 2008b). This contradiction is apparently justified in Future Water (DEFRA, 2008a), the Government's water strategy for England, with the statement that "As greywater recycling systems - and some rainwater harvesting systems - require energy for treatment and pumping we do not think it appropriate to mandate these types of systems within all buildings". This highlights the gap between rhetoric and action as well as a problem common in relation to water management in the policy making and planning sectors; that policy makers and implementers do not wish to be seen as "favouring" certain technologies over others (Bulkeley, 2006).

This does not seem problematic in relation to energy efficiency and the promotion of micro-renewables in buildings. Robinson (2006) highlights that realisation of an improvement of the energy efficiency of buildings depends on financial incentives, information, building code standards and appropriately positioned public policy, along with intergovernmental harmony and a more actively engaged polity and civil society. There are strong parallels to be drawn here with an increase in the water efficiency of buildings. Although the latter two points are somewhat harder to achieve, steps have been taken towards providing these services for energy: there is an array of Government funded mechanisms (via the Carbon Trust) and financial incentives (such as the Low Carbon Buildings Programme). In relation to water, limited support mechanisms are provided by Envirowise; a business-orientated body not dedicated purely to promoting water efficiency and the enhanced Capital Allowance Scheme for the Water Technology List, which again only applies to businesses. Anecdotal evidence suggests that even this is not enough to support businesses in what they would like to do (Hodgson, 2008). Furthermore the Government seems immovable in its stance of providing no further financial incentives for RWH, for example for homeowners: "There are however no plans for an additional dedicated fund to give grants for this technology" (DEFRA, 2008c).

In light of this 'encouragement' rather than 'requirement' philosophy, the second question is how do we address and reduce the RWH implementation deficit? The limitations of the policy vehicles outlined above place responsibility for the understanding and initiation of the implementation process, as well as a significant financial burden, on 'people' (householders, businesses, developers). It is therefore important to understand the motivations and requirements of a range of stakeholders, if they are to be enabled to seriously consider such a resource intensive undertaking. This paper presents results from the preliminary stages in the development of an evidence-based framework, which aims to address the implementation deficit and facilitate an increase in the willingness and ability of a range of stakeholders to implement RWH. 


\section{METHODOLOGY}

The overall approach to the research uses grounded theory analysis (Robson, 2002), in order to identify the current gaps in supporting the willingness and ability of stakeholders to implement RWH and hence develop the framework. The first stage is to build an evidence base to address both recognised knowledge gaps and to identify others, using inductive and deductive thinking. A range of both engineering and social science methodologies are being used to build technical and stakeholder insight evidence bases and these are summarised in Table 1. The specific methodologies used to collect the data within each evidence base are not described here in detail due to space limitations.

Table 1. Components of the research evidence base.

\begin{tabular}{|c|c|c|}
\hline \multirow{5}{*}{$\begin{array}{l}\text { Technical } \\
\text { Evidence } \\
\text { Base }\end{array}$} & Category & Collection Method \\
\hline & $\begin{array}{l}\text { System design } \\
\text { evaluation }\end{array}$ & Use of RainCycle (C) to analyse supply/demand balance \\
\hline & System performance & Water meters connected to Building Management System \\
\hline & Demand profiling & Automated WC flush counter with integrated logger \\
\hline & Rainwater quality & Standard sampling and analysis techniques \\
\hline \multirow{2}{*}{$\begin{array}{l}\text { Stakeholder } \\
\text { Insight } \\
\text { Evidence } \\
\text { Base }\end{array}$} & Stakeholder Group & Collection Method \\
\hline & $\begin{array}{l}\text { (i) Householders*^ } \\
\text { (ii) Small to medium } \\
\text { enterprises (SMEs)* } \\
\text { (iii) Schools* } \\
\text { (iv) Architects** }\end{array}$ & $\begin{array}{l}(*) \text { RWH system user/non-user perception and experience } \\
\text { questionnaires/surveys and interviews; }\left({ }^{\wedge}\right) \text { Focus groups; } \\
(* *) \text { Design consideration, documentation and experience } \\
\text { questionnaires/surveys and interviews; }\end{array}$ \\
\hline
\end{tabular}

After analysing results from the two evidence bases (open coding), the next step in building the framework is to construct cognitive maps of problem areas and weak links (themes) - this is likened to the axial coding stage in grounded theory analysis. These maps can be used to identify the main categories (selective coding) to address in relation to enhancing the willingness and ability of stakeholders to implement RWH. Finally, these categories will be used to develop both technology and policy based recommendations and guidelines; the final stage of the framework development. The process is summarised in Figure 1.

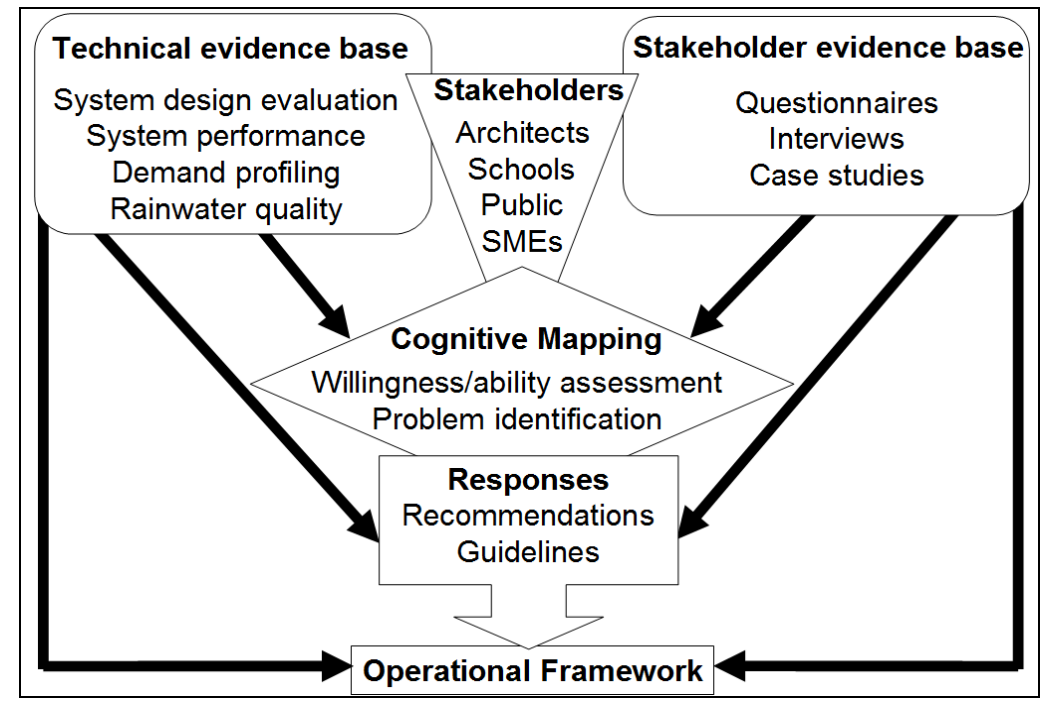

Figure 1. Basic structure of the framework process. 


\section{RESULTS}

\section{Technical evidence base}

System design evaluation. Two design evaluations have been undertaken - one for a series of communal residential RWH systems and one for a single RWH system in a new office building in order to assess methods currently used by stakeholders to design RWH systems. Results revealed that installed systems were over-sized in terms of their supply-demand balance, indicating the methods used were not the most suitable. Smaller, cheaper systems could have been implemented which would have achieved a similar level of water saving in each case. Additionally, roof sizes were not considered carefully during the system design stage.

System performance. Water meters are being used to quantify the volume of rainwater utilised within an office building, in order to demonstrate the level of saving (in both water and financial terms) achieved by a commercial RWH system. Unfortunately, the system was misconfigured during its first year of operation, resulting in more mains water being used than rainwater. This has now been rectified and recent data indicates that rainwater consumption is in excess of mains. Full analysis is currently being undertaken.

Demand profiling. In order for stakeholders to consider implementing $\mathrm{RWH}$, they must first understand how they may benefit. Currently non-domestic demand profiles are not well documented, which can result in miscalculation of the supply/demand balance when designing RWH systems. Bespoke WC flush counters have been designed and installed in the aforementioned office building. Initial results indicate that non-domestic profiles are different to domestic profiles (which demonstrate peaks in the morning and evening) having peaks mid-morning, lunchtime and midafternoon. Additionally, full flushes occur approximately twice as often as partial flushes, which was unexpected.

Rainwater quality. Data relating to rainwater quality is limited for the UK, providing little reassurance to stakeholders that RWH systems pose a low hazard. Results from the office-building study indicate physiochemical determinands represent little hazard, although there are system function implications, such as potential for copper and zinc corrosion due to water being soft (low calcium content). Poor detailing on the structure of the roof has resulted in avian faecal matter deposits, resulting in Enterococcus faecalis (a type of bacteria) counts above recommended guideline levels (Figure 2). Remedial actions have had to be implemented to overcome these issues.

\section{Stakeholder insight evidence base}

Householders. Questionnaires were administered to two residential areas - one new development with communal RWH systems (Broadclose) and one well-established development without RWH (Littleham). Results of the survey indicated that overall there was a high willingness to consider RWH, but without incentives, such as financial savings or access to grants (Figure 3), respondents indicated their ability to implement was low. Additionally it was found that respondents' knowledge (in both groups) of system maintenance requirements was extremely limited, in terms of both practicalities and cost. In relation to information provision, respondents showed a preference for a leaflet with their water bill from water service providers (WSPs). 


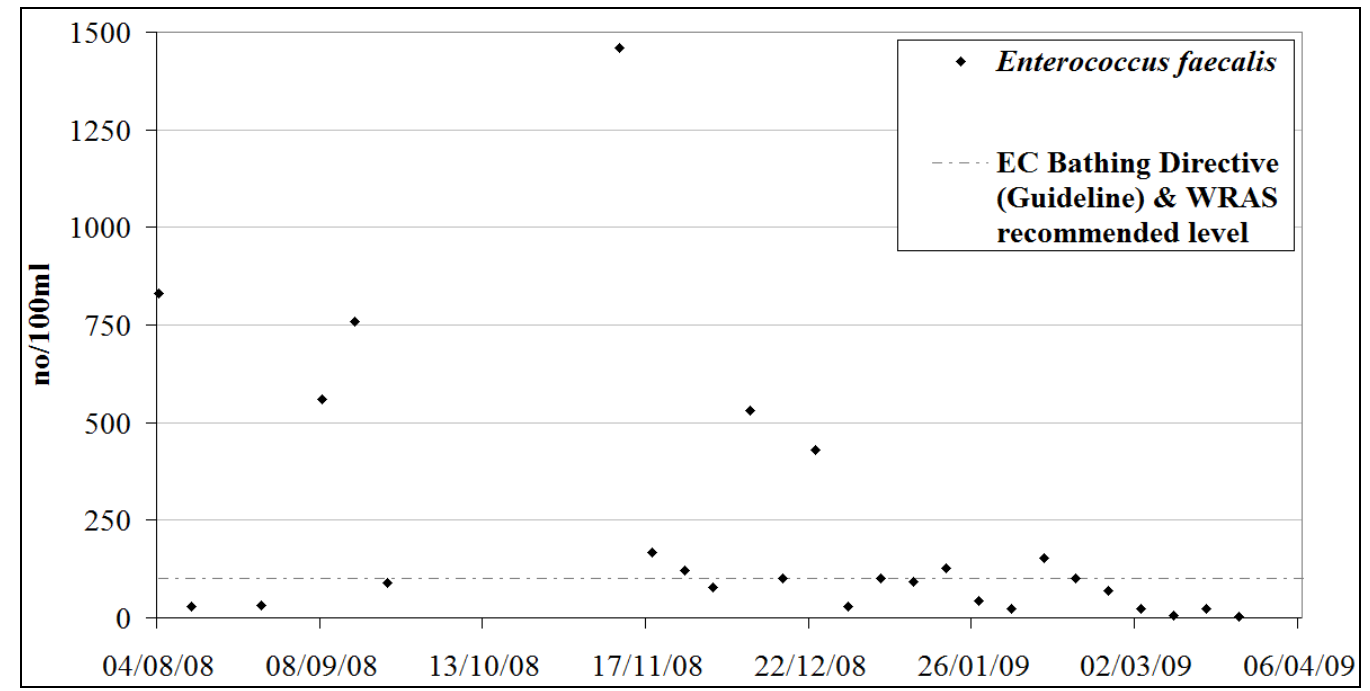

Figure 2. Enterococcus faecalis counts from the office-building water quality study.

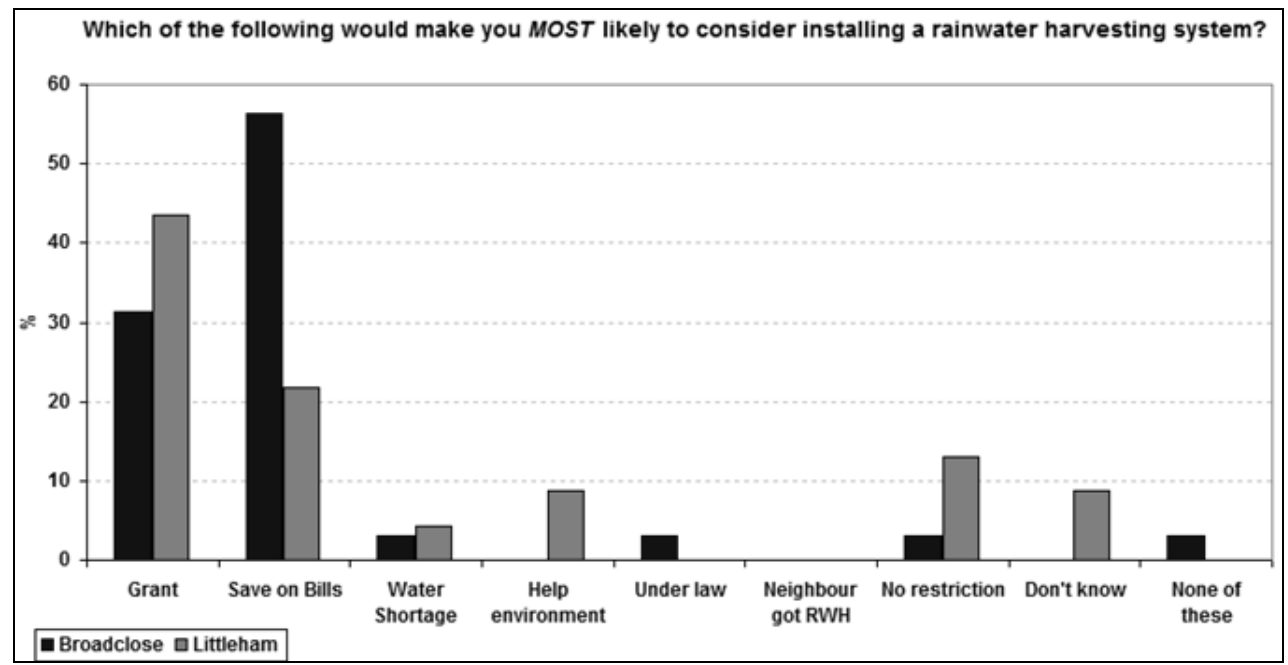

Figure 3. Responses to a question on factors encouraging consideration of RWH.

Architects. A questionnaire was administered, which asked about, (i) in-house expertise on alternative water resources (such as RWH and greywater reuse); and (ii) use of/experience with alternative techniques and documentation. Results showed that there was a divide between those who had expertise and had used appropriate documentation and others that did not. One project described as having 'teething' problems was overseen by an architect with no expertise in alternative techniques who had very low knowledge of relevant documentation (had heard of, but not used, only one out of six highly relevant reports, guides or standards). A second project had a roof designed and constructed from a material (copper) highlighted as having water quality implications in the most recent standard (BSI, 2009).

Schools. Case studies of an existing school aspiring to retrofit a RWH system, a new build school with RWH and two new build schools without RWH were conducted to identify obstacles to implementing RWH. The two new build schools without RWH were built before new Government schemes were released (including BREEAM Education (BREEAM, 2008) - previously BREEAM Schools), which require water usage to be considered during the design/refurbishment process - facilitating consideration of RWH. Through interviews it transpired that RWH was value- 
engineered out of the two new builds without RWH. For the aspirational retrofit school it became apparent that the willingness of parties involved (staff, head teacher) was high, but their ability to implement was low and relied heavily on the local authority. Identifying guidance and financial support to enable these schools to retrofit RWH was not straightforward.

SMEs. Questionnaires and interviews have been and are still being conducted with SMEs in the following categories:

1. SMEs which had not heard of RWH;

2. SMEs which had heard of RWH, but no more;

3. SMEs which had heard of RWH and tried to implement it, but unsuccessfully;

4. SMEs which had heard of RWH and implemented it successfully.

A range of SMEs are involved, from office-based businesses, to hotels, cafes and charities. Despite the previously outlined support mechanisms, anecdotal evidence was reinforced, as implementation was not straightforward. Although one SME reported receiving excellent support from a WSP in relation to retrofitting water efficient products (including a water audit), little advice was given regarding RWH. Additionally the local planning department was identified as being very unhelpful, with regard to a system fitted within a Grade II listed building. Other SMEs highlighted not being able to find out where systems had been fitted to a similar size and type of business, so that they could see how RWH was performing.

\section{DISCUSSION AND RECOMMENDATIONS}

Axial coding (also known as 'memoing') activities have been initiated and relationships between themes from evidence bases are being established (summarised in Figure 4). Figure 4 demonstrates that the network involved in implementing RWH systems is complex and convoluted. Although some aspects of the research are still on going (such as SME interviews and technical data collection), consistent deficit themes ('categories') are beginning to emerge (also summarised in Figure 4).

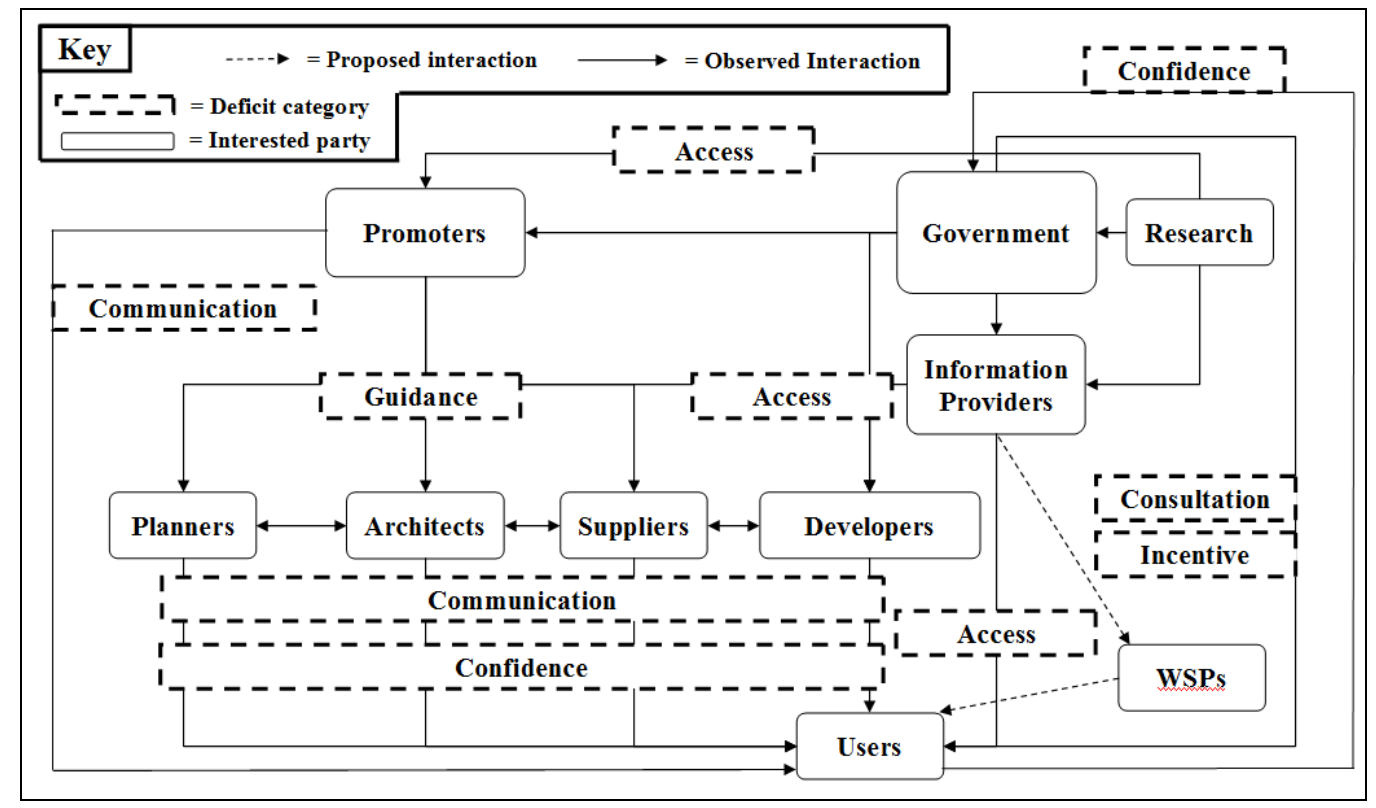

Figure 4. Identification of deficit categories during the analysis phase. 
Deficit categories identified so far include:

- Communication

- Confidence
- Access

- Incentives
- Guidance

- Consultation

Communication, Access and Guidance. Data from both evidence bases supports the view that there is a lack of communication of and access to general information on RWH - with much information being duplicated by different providers. Additionally, schemes and leaflets by organisations tasked with supporting RWH (such as Envirowise) were unheard of by the SMEs interviewed. Both householders and SMEs viewed WSPs as their first point of contact, therefore WSPs may need to promote measures beyond water efficient devices. Furthermore there appears to be a lack of communication of and access to appropriate design and maintenance guidance. Performance and water quality issues arising from system misconfiguration and poor consideration of roof design (size, structure and material) highlight that there is an inadequate understanding of the importance of buildings in relation to RWH systems. Additionally, knowledge of maintenance commitments was limited across stakeholder groups. Although a range of guidance material exists, awareness of it and its actual usage is inconsistent. At present, communication of and access to information is uncoordinated. Direct communication between stakeholders during the implementation of RWH systems was also limited. Architects did not consult system suppliers regarding building or roof design features which would need to be taken into account in the RWH system design (such as extra treatment measures where roostingprone or ground-level catchments were to be included). Where such problems arose, building managers were tasked with resolving and funding remediation measures. If policy promotion rhetoric is to be turned into enabling action, information promoters and providers may need to rethink their current dissemination and coordination strategies.

Confidence, Incentives and Consultation. Both householders and SMEs reported demonstration sites would be more likely to encourage them to consider installing RWH. One SME suggested a 'buddy' system that would allow similar sized businesses with RWH to mentor those considering an installation. This would enhance their confidence about systems and provide guidance on the implementation process. Greater dissemination of performance and water quality data (such as that collected during this research) would also help to reinforce confidence in RWH, reassuring stakeholders of the low hazard posed (where buildings/systems are designed correctly) and reinforcing the cost-benefits possible. Financial incentives were identified to be a significant factor in the ability of stakeholders to implement. Several stakeholders reported having to think creatively and 'outside the box' in terms of the funding proposals they submitted to various organisations in a bid to secure funding to implement RWH, which was both time consuming and frustrating. One charity-based project (for which a detailed feasibility study had been conducted) had been on hold for over a year, as appropriate funding could not be secured to purchase and install equipment. ECAs were rarely claimed, as amounts claimable were less than accountant's fees. This demonstrates that the current Government strategy to provide incentives does not meet the needs of the stakeholders they are aiming to encourage implementing RWH. Furthermore, these categories emphasize that greater consultation is required in order to identify areas with which stakeholders require additional support. 


\section{CONCLUSION}

The research has used a novel and interdisciplinary approach (social science perspectives applied to an engineering response) to develop a framework to facilitate implementation of RWH in the UK. Technical and stakeholder evidence bases have been established. At present six categories of deficit have been identified, which indicate a lack of enabling of stakeholders. These areas require addressing for policy rhetoric to actively support implementation. Recommendations highlight the need for coordinated information provision and reconsideration of incentive schemes to support the willingness and ability of interested parties to implement RWH systems.

\section{ACKNOWLEDGEMENTS}

This work was carried out as part of the 'Water Cycle Management for New Developments' (WaND) project (www.wand.uk.net) funded under the Engineering \& Physical Science Research Council's “Sustainable Urban Environment” Programme.

\section{REFERENCES}

BREEAM (2008) BREEAM Education.

http://www.breeam.org/page.jsp?id=20 (accessed 13 August 2008)

BSI (2009) BS 8515:2009: Rainwater harvesting systems: Code of practice. BSI, London, UK. http://www.bsi-global.com/en/Shop/PublicationDetail/?pid=000000000030171876 (accessed 05 February 2009)

Bulkeley, H. (2006) A Changing Climate for Spatial Planning. Planning Theory \& Practice, Vol. 7, No. 2, 203-214.

DEFRA (2008a) Future Water.

http://www.defra.gov.uk/environment/water/strategy/pdf/future-water.pdf (accessed 08 February 2008)

DEFRA (2008b) Progress Report on Sustainable Products and Materials. http://www.defra.gov.uk/environment/consumerprod/pdf/prod-materialsreport0708.pdf (accessed 13 August 2008)

DEFRA (2008c) Nieves Bottomley, Head of DEFRA Water Saving Group, Personal Communication.

Hassell, C. (2005). Rainwater harvesting in the UK - a solution to increasing water shortages? Proceedings of the 9th International Conference on Rainwater Catchment Cistern Systems. Petrolina, Brazil.

Hodgson, M. (2008) Discussion on rainwater harvesting and SMEs. Global Action Plan. Personal Communication.

Robinson, P. (2006) Canadian Municipal Response to Climate Change: Measurable Progress and Persistent Challenges for Planners. Planning Theory \& Practice, Vol. 7 , No. 2, 218-223.

Robson, C. (2002) Real World Research. Blackwell, Oxford, UK.

Sustainable Buildings Task Group (2004) Better Buildings-Better Lives. http://www.berr.gov.uk/files/file15151.pdf (accessed 13 August 2008). 